\title{
Mechanism of c-myc Regulation by c-Myb in Different Cell Lineages
}

\author{
JOHN P. COGSWELL, ${ }^{1}$ PATRICIA C. COGSWELL, ${ }^{1}$ W. MICHAEL KUEHL, ${ }^{2}$ AGNES M. CUDDIHY, ${ }^{2}$ \\ TIMOTHY M. BENDER, ${ }^{3}$ UTE ENGELKE, ${ }^{4}$ KENNETH B. MARCU, ${ }^{5}$ AND JENNY P.-Y. TING ${ }^{1,6 *}$ \\ Lineberger Comprehensive Cancer Center ${ }^{1 *}$ and Department of Microbiology and Immunology, ${ }^{6}$ University of \\ North Carolina, Chapel Hill, North Carolina 27599-7295; Navy Medical Oncology Branch, National Cancer \\ Institute, Bethesda, Maryland 208922; Department of Microbiology and Immunology, University of Virginia, \\ Charlottesville, Vinginia 2290333; and Department of Biochemistry and Cell Biology and Department of \\ Microbiology, ${ }^{4}$ State University of New York, Stony Brook, New York 11790
}

Received 10 July 1992/Returned for modification 18 September 1992/Accepted 16 February 1993

\begin{abstract}
Activation of the murine c-myc promoter by murine c-Myb protein was examined in several cell lines by using a transient expression system in which Myb expression vectors activate the c-myc promoter linked to a chloramphenicol acetyltransferase reporter gene or a genomic $\beta$-globin gene. S1 nuclease protection analyses confirmed that the induction of c-myc by c-Myb was transcriptional and afiected both P1 and P2 start sites in a murine T-cell line, ELA, and a myelomonocytic line, WEHI-3. Mutational analyses of the c-myc promoter revealed that two distinct regions could confer Myb responsiveness in two T-cell lines, a distal site upstream of $P 1$ and a proximal site within the first noncoding exon. In contrast, only the proximal site was required for other cell lineages examined. Five separate Myb-binding sites were located in this proximal site and found to be important for c-Myb trans activation. DNA binding was necessary for c-myc activation, as shown by the loss of function associated with mutation of Myb's DNA-binding domain and by trans-dominant repressor activity of the DNA binding, trans-activation-defective mutant. The involvement of additional protein factors was addressed by inhibiting protein synthesis with cycloheximide in a conditional expression system in which the activity of presynthesized Myb was under the control of estrogen. These experiments indicate that de novo synthesis of additional proteins was not necessary for c-myc trans activation. Together these data reveal two cell lineage-dependent pathways by which c-Myb regulates c-myc; however, both pathways are mechanistically indistinguishable in that direct DNA binding by Myb is required for activating c-myc whereas neither de novo protein synthesis nor other labile proteins are necessary.
\end{abstract}

c-myb and c-myc are members of the nuclear protooncogene family $(13,31,32,48)$. The expression of c-myc mRNA and that of $c-m y b$ mRNA are each correlated with cell proliferation and differentiation $(13,31,32,48)$. Expression of both proto-oncogenes increases dramatically when lymphocytes are induced by mitogens or growth factors to enter the cell cycle $(13,31,32,48,52)$. They are expressed at high levels in immature hematopoietic cells $(13,31,32,48$, $52,55)$ and decrease in a biphasic manner during terminal differentiation $(11,12,33,34,47,53)$. Unlike c-myc, which is ubiquitous, c-myb is preferentially expressed in cells of hematopoietic origin, suggesting that c-Myb may be an important regulator of hematopoiesis $(13,31,32,48,55)$.

Experimental evidence supports respective roles for each gene product in proliferation or differentiation control. Antisense DNAs $(1,16,18,21,59)$ specific for either gene will inhibit the proliferation of myeloid leukemia cells and $T$ cells. Constitutive overexpression of c-myc or c-myb mRNA in vivo can prevent terminal differentiation in certain cell types $(11,12,33,34,47,53)$ or enhance competence for cell cycle progression $(14,54)$. Antisense oligonucleotides complementary to c-myb mRNA can inhibit colony formation by hematopoietic progenitor cells in vitro (19). Likewise, in vivo inactivation of the c-myb gene results in defective hematopoiesis (35). Recent data demonstrating that c-Myb protein can activate c-myc gene expression (15, 36, 60) suggest that their expression might be functionally linked

\footnotetext{
* Corresponding author.
}

rather than merely parallel. Therefore, it becomes imperative to understand how the Myb protein might regulate c-myc gene expression.

The c-Myb protein and its oncogenic homologs encoded by the avian myeloblastosis virus (AMV) and E26 leukemia virus appear to be transcriptional regulators $(15,24,26,37$, $39,46,57)$. These proteins bind to specific DNA sequences, and tandem repeats of these Myb regulatory elements (MREs) will confer Myb-specific regulation to an unresponsive promoter $(17,22,36,39,46,57,60)$. Likewise, structural domains previously identified by their similarity to known transcription factors have been shown to mediate Myb's activation function $(31,48)$. For c-Myb, these domains encode DNA-binding, trans-activator, and negative regulatory functions $(22,25,26,28,45,46)$. The DNAbinding domain is contained within an amino-terminal region consisting of three 50 -amino-acid repeats $(31,48)$. These consecutive repeats (R1, R2, and R3) contain a high percentage of basic amino acids and a conserved spacing of relatively rare tryptophan residues $(31,45,48)$. Of the three repeats, only $R 2$ and $R 3$ are required for DNA binding (22, $45,57)$. c-Myb contains a leucine zipper-like structure which may be involved in interaction with other proteins (26). The leucine zipper is contained within a larger negative regulatory domain whose deletion potentiates Myb's trans-activation function $(24,26,46)$. A trans-activator domain has been localized to an acidic region in the center of the c-Myb protein $(26,46,57)$. Transduced $v-M y b$ proteins are invariably truncated compared with c-Myb and appear to be more potent transcriptional activators $(20,24,25,46,57)$. Reten- 
tion of the DNA-binding and trans-activator domain concomitant with loss of the negative regulatory domain or a small amino-terminal domain whose phosphorylation inhibits DNA binding in $\mathbf{v}-\mathrm{Myb}$ proteins appears to be a key feature in transformation $(20,24-26,30,46,57)$.

Several cellular genes whose expression is regulated by Myb have been identified. A current list of Myb-regulated genes includes the human c-myb, lysozyme, Hsp70, mim-1, MD- 1 , and CD4 genes $(9,28,39,40,51)$. The presence of Myb-binding sites in the promoter sequences of the mim-1 and $c-m y b$ genes appears, in part, to confer responsiveness to the Myb protein $(39,40)$. Other genes may be regulated indirectly. For example, the Hsp70 promoter can be trans activated by DNA binding-defective Myb mutants (28). Likewise, activation of the MD-1 gene is blocked by protein synthesis inhibitors (9). Human and murine c-myc also contain Myb-binding sites and are trans activated by c-Myb $(15,36,60)$; however, a direct link between Myb binding and trans activation has not been established.

In this study, c-myc trans activation by c-Myb was analyzed in several cell lineages and lineage-specific mechanisms were revealed. We further explored the activation pathway in detail and showed that Myb binding to sites within the first exon was required. Neither de novo protein synthesis nor labile protein factors were necessary. We also show that both P1 and P2 transcription was induced by Myb.

\section{MATERIALS AND METHODS}

Cell lines. The EL4, WEHI-3, L929, and BW5147 cell lines were obtained from the Lineberger Comprehensive Cancer Center Tissue Culture Facility. WEHI-231 was a gift of David W. Scott, University of Rochester. The cell line CH12.LX2 was provided by Geoffrey Haughton, University of North Carolina. C33 cells were provided by Shannon Kenney, University of North Carolina. The PU5-1.8 cell line (ATCC TIB 61) was obtained from the American Type Culture Collection, Bethesda, Md. EL4, WEHI-3, C33, WEHI-231, L929, and BW5147 cells were all grown in Dulbecco modified Eagle medium-H (DMEM-H) supplemented with $7.5 \%$ fetal calf serum, $100 \mu \mathrm{g}$ of streptomycin per $\mathrm{ml}, 100 \mathrm{U}$ of penicillin per $\mathrm{ml}, 0.1 \mathrm{mg}$ of gentamicin per $\mathrm{ml}, 1 \mathrm{mM}$ sodium pyruvate, $1 \mathrm{mM}$ nonessential amino acids, $2 \mathrm{mM}$ glutamine, and $5 \times 10^{-5} \mathrm{M} 2$-mercaptoethanol. $70 \mathrm{Z} / 3$, 402AX, CH12.LX2, and PU5.1R cells were grown in RPMI 1640 medium with the same supplements. EL4 and WEHI-3 cells were also adapted to growth in phenol red-free DMEM-H.

Plasmids. Construction of pMBgCAT, pSmBgCAT, pMBgCAT(2-36), pMBgXhCAT, and pMBg96CAT reporter genes has been described elsewhere $(2,44)$. pMBgCAT $(\Delta \mathrm{Aw}-\mathrm{Sm})$ and $\mathrm{pMBgCAT}(\Delta \mathrm{Bx}-\mathrm{Sm})$ were constructed from pMBgCAT by partial digestion with, respectively, the $A l$ $w \mathrm{NI}$ and BstXI restriction enzymes, blunt ending the $3^{\prime}$ protruding ends with T4 DNA polymerase (Boehringer Mannheim), digestion with $S m a$ I enzyme to release the $A l w$ NISmaI or BstXI-SmaI fragment, and ligation of the vector. Reporter genes $\operatorname{pMBg}(\Delta \mathrm{Hd}-\mathrm{Xh}), \operatorname{pMBg}(\Delta \mathrm{Hd}-\mathrm{Nt})$, and $\operatorname{pMBg}(\Delta \mathrm{Nt}-\mathrm{Xh})$ were prepared from $\mathrm{pMBgCAT}$ by digestion with the HindIII, NotI, or XhoI restriction enzyme to release the corresponding HindIII-XhoI, HindIII-NotI, or NotIXhoI fragment; blunt ending the $5^{\prime}$ protruding ends with Klenow polymerase (Boehringer Mannheim); and vector ligation. $\mathrm{pSmBg}(\Delta \mathrm{Hd}-\mathrm{Xh})$ and $\mathrm{pSmBg}(\Delta \mathrm{Nt}-\mathrm{Xh})$ are the corresponding deletions made in pSmBgCAT. pSVM $(H)_{R} C A T$ contains the HindIII-BglII first exon fragment of c-myc cloned downstream of the simian virus 40 (SV40) promoter. The c-myc fragment contains 24 bp 5' of the P2 initiation site but lacks the TATA box positioned 28 to $32 \mathrm{bp} 5^{\prime}$ of this start site. Previous work has shown that the P2 start site is silent and that transcription initiates from E1 and E2 start sites of the SV40 promoter (58).

Site-specific mutants of putative Myb-binding sites 11 to 15 were made by Kunkel mutagenesis. Briefly, the BglII$B g l$ II fragment of the murine c-myc promoter was subcloned into the $B g l I I$ site of pSG5 (Stratagene). Template strands of c-myc were prepared by M13K07 helper phage rescue in Dut $^{-}$Ung $^{-}$CJ236 bacteria. Mutant oligonucleotides were annealed, and second-strand synthesis was completed with T4 DNA polymerase and deoxynucleoside triphosphates. Circular templates were transformed into $\mathrm{DH} 5 \alpha$ bacteria, and mutant sequences were confirmed by dideoxy sequencing. The $B g l I I-B g l I I$ fragment containing mutant Myb sites was subcloned into pCAT $(\triangle \mathrm{EP})$ for transient transfections.

The wild-type Myb expression vector $p R m b 3 S V n e o$ and frameshift mutant pJTmyb-fs were constructed as described previously $(15,33)$. pJTmyb-fs lacks 7 bp $3^{\prime}$ to the Bst XI site of murine c-Myb. Construction of $\mathrm{c}-\mathrm{Myb}$ expression plasmids is as follows. The c-myb deletion mutants were first constructed in a pBluescript SK vector containing the $2.2-\mathrm{kb}$ SmaI-BglII fragment from c-myb cDNA (4) in which SmaI and $B g l$ II sites had been converted to HindIII and BamHI, respectively. A HindIII-BamHI fragment containing each mutated c-myb construct was gel purified from pBluescript (Stratagene) or pGEM (Promega) vectors and cloned into the Rous sarcoma virus vector $\mathrm{pRmb3SVneo} \mathrm{lacking} \mathrm{the} \mathrm{neo-}$ mycin gene. C-terminal deletions have the last 14 amino acids and the termination codon. The map in Fig. 6A details which amino acids have been deleted.

pNEO-AMV is an AMV v-myb expression vector which contains a provirus, and its transcription is driven by the long terminal repeat (25). pNEO-MAV-CLA is a control plasmid in which the KpnI-XbaI v-myb fragment of pNEOAMV has been deleted and replaced by a ClaI linker (25). pNEO-Myb-E is a v-myb-estrogen receptor fusion vector in which the hormone-binding domain of the human estrogen receptor has been fused in frame at the Ball site. The carboxyl-terminal 16 amino acids of v-Myb was deleted in this process. pNEO-Myb-E was derived from Neo-AMV$\Delta \mathrm{GE}(25)$ and lacks gag and $e n v$ sequences.

The pBS-globin plasmid (a gift of F. Furnari, University of North Carolina) was constructed by inserting a blunt-ended 2.2-kb HindIII-XbaI fragment of pSP64HDB6 (29) which contained the genomic sequence for the $\beta$-globin gene into the SmaI site of pBS+ (Stratagene). The murine c-myc promoter was cloned into pBS-globin in two steps to make pMyc-globin as follows. The BglII-BglII c-myc promoter fragment from pMBgCAT was isolated, blunt ended with Klenow polymerase, and ligated into the HincII site of pBS+ (Stratagene). The c-myc promoter was subsequently removed as two fragments, $X b a I-H i n d I I I$ and HindIII$H$ indIII, by digestion with $X b a I$ and HindIII restriction enzymes. Both fragments were ligated into the $X b a I$ to HindIII site of pBS-globin, and directional ligation was confirmed by restriction mapping and double-stranded dideoxy sequencing.

Transient transfections and chloramphenicol acetyltransferase (CAT) assays. All cells were seeded at low densities and grown to log phase over $48 \mathrm{~h}$ prior to transfection. Subconfluent monolayers of adherent WEHI-3, PU5-1.8, and C33 cells were used. The cells were transfected with a Bio-Rad gene pulser as described elsewhere (50). Transfec- 
TABLE 1. Cell-specific activation of c-myc-CAT expression by c-Myb

\begin{tabular}{|c|c|c|c|c|c|}
\hline \multirow{2}{*}{ Cell type } & \multirow{2}{*}{$\begin{array}{l}\text { Cell line } \\
\text { name }\end{array}$} & \multirow{2}{*}{$\begin{array}{l}\text { No. of } \\
\text { expts }\end{array}$} & \multirow{2}{*}{$\begin{array}{l}\text { Fold trans activation } \\
\text { of c-myc by c-Myb }\end{array}$} & \multicolumn{2}{|c|}{ Requires MRR that is ${ }^{b}$ : } \\
\hline & & & & Proximal & Distal \\
\hline Thymoma & EL4 & 4 & $10.3 \pm 0.5$ & + & + \\
\hline Thymoma & BW5147 & 2 & $6.8 \pm 1.8$ & + & + \\
\hline B lymphoma & $\mathrm{CH} 12$ & 2 & $6.0 \pm 0.2$ & ND & ND \\
\hline B lymphoma & WEHI-231 & 4 & $9.4 \pm 1.1$ & + & - \\
\hline Pre-B lymphoma & $70 Z / 3$ & 3 & $\begin{array}{c}1.2 \pm 0.2 \\
(6.3 \pm 0.5)\end{array}$ & ND & ND \\
\hline Myeloid & PU5-1.8 & 3 & $36.0 \pm 11.0$ & ND & ND \\
\hline Myeloid & WEHI-3 & 3 & $21.4 \pm 0.8$ & + & - \\
\hline Embryonal carcinoma & $402 \mathrm{AX}$ & 4 & $3.0 \pm 0.4$ & ND & ND \\
\hline Fibroblast & L929 & 2 & $1.0 \pm 0.3$ & ND & ND \\
\hline Epithelial & $\mathrm{C} 33$ & 2 & $2.0 \pm 0.3$ & ND & ND \\
\hline
\end{tabular}

a All experiments were performed at a 1:1 ratio of Myb expression vector to pMBgCAT, except that $70 \mathrm{Z} / 3$ cells were transfected at both $1: 1$ and 4:1 ratios (the latter result is shown in parentheses).

$b$ ND, comparison was not done.

tions were generally performed in the same medium as was used for growth. Cells grown in phenol red-free DMEM-H for estrogen inductions were transfected in $1 \times$ phosphatebuffered saline with $7.5 \%$ fetal calf serum. Transfection conditions were varied for each cell line to obtain optimal transfection efficiency. EL4, BW5147, WEHI-231, 70Z/3, and CH12.LX2 cells were electroporated at $240 \mathrm{~V} / 960 \mu \mathrm{F}$. All other cells were electroporated at $200 \mathrm{~V} / 960 \mu \mathrm{F}$. Reporter plasmid concentrations used were generally $5 \mu \mathrm{g}$ for each cell line. The concentrations of Myb expression vectors were usually $1: 1$ with the reporter gene except in estrogen induction experiments, in which 10:1 ratios were used. Cells were usually harvested for CAT assay $24 \mathrm{~h}$ posttransfection unless otherwise indicated. CAT assays were performed as described previously (50). The average enzyme assay was 1 to $2 \mathrm{~h}$ for ELA and 4 to $24 \mathrm{~h}$ for other cell lines. Percent acetylation was quantified by cutting out sections of the thin-layer chromatography plate that corresponded to these two forms, followed by scintillation counting.

RNA isolation and S1 nuclease protection analysis. Cells were harvested for RNA preparation $24 \mathrm{~h}$ posttransfection. Total cellular RNA was recovered by lysis of transfected cells in guanidine-thiocyanate and pelleting through $\mathrm{CsCl}$ as described elsewhere (10). Uniformly labeled antisense probes for murine c-myc were prepared by primer extension of a single-stranded DNA template copy of the pMyc-globin reporter plasmid. Template sense strands of pMyc-globin were prepared by M13KO7 helper phage rescue. The globin-2 primer 5'-CAGTAACGGCAGACTTG-3' was annealed to the first exon of human globin sequence, and extension was carried out with Klenow polymerase using $\left[\alpha{ }^{32} \mathrm{P}\right] \mathrm{dATP},\left[\alpha-{ }^{32} \mathrm{P}\right] \mathrm{dCTP}$, and unlabeled dGTP and dTTP. After digestion with SmaI, the strands were separated on a 4\% denaturing polyacrylamide-urea gel. Probe bands were excised and eluted in $0.5 \mathrm{M}$ sodium acetate- $0.1 \%$ sodium dodecyl sulfate solution. Annealing reactions were set up with $100,000 \mathrm{cpm}$ of antisense DNA probe and $30 \mu \mathrm{g}$ of RNA, and hybridization reactions were carried out overnight at $58^{\circ} \mathrm{C}$ in a solution of $80 \%$ formamide, $40 \mathrm{mM}$ PIPES [piperzidine- $N, N^{\prime}$-bis(2-ethanesulfonic acid)], $400 \mathrm{mM} \mathrm{NaCl}$, and $1 \mathrm{mM}$ EDTA. Samples were digested with $400 \mathrm{U}$ of S1 nuclease (Bethesda Research Laboratories) as described previously (6) and then electrophoresed through a $4 \%$ denaturing polyacrylamide-urea gel along with HaeIII-cut pBR322 markers. Protected bands were detected by autoradiography.
Estrogen induction and cycloheximide treatment. The pNEO-Myb-E expression vector converts the $\mathrm{v}-\mathrm{Myb}$ protein to an estrogen-inducible trans activator by fusing the hormone-binding domain of the human estrogen receptor to a carboxyl-truncated $\mathrm{v}-\mathrm{Myb}$ protein. To measure estrogen induction of the Myb-estrogen receptor fusion protein, EL4 and WEHI-3 cells were adapted to growth in phenol red-free DMEM-H (phenol red is a weak estrogen). It was not necessary to remove estrogen from the fetal calf serum since the concentrations were not high enough to interfere with estrogen induction. EL4 and WEHI-3 cells were induced with a $1 \mu \mathrm{M}$ final concentration of $\beta$-estradiol (Sigma catalog no. E-2758). To determine the need for de novo protein synthesis in Myb function, estrogen-dependent activation of the Myb-estrogen receptor fusion protein was measured in the presence of the protein synthesis inhibitor cycloheximide. Cycloheximide was added $20 \mathrm{~min}$ prior to estrogen induction to a final concentration of $50 \mu \mathrm{g} / \mathrm{ml}$, which inhibited protein synthesis virtually completely as measured by $\left[{ }^{35} \mathrm{~S}\right]$ methionine incorporation (data not shown). Cells were treated with estrogen and cycloheximide either alone or in combination for $5 \mathrm{~h}$ prior to RNA preparation. Changes in c-myc promoter activity were measured by $\mathrm{S} 1$ nuclease protection analyses from the cotransfected pMyc-globin plasmid.

\section{RESULTS}

The magnitude of Myb activation of the c-myc gene is cell type dependent. Previously, we showed that a Rous sarcoma virus long terminal repeat-driven $\mathrm{c}-\mathrm{Myb}$ expression vector could activate a 1.7-kb c-myc promoter fragment linked to a CAT reporter gene in T cells (15). To determine whether the trans activation of c-myc by c-Myb occurs in different cell types, we examined the panel of murine cell lines shown in Table 1. These plasmids were introduced at a 1:1 ratio and in one case at a 4:1 ratio of the Myb expression vector to pMBgCAT. Myb trans activation of c-myc (expressed as fold trans activation) was normalized both to a frameshift mutant of the Myb expression vector and to a promoterless reporter gene.

The data in Table 1 clearly demonstrate that Myb can activate the c-myc promoter in cell types other than $T$ cells. Some level of response was elicited in most cell types; however, the magnitude of the responses clearly differed and in general segregated according to cell type. Very modest 
responses were seen in nonhematopoietic $402 \mathrm{AX}$ embryonal carcinoma (threefold), L929 fibroblast (onefold), and C33 epithelial (twofold) cells at 1:1 ratios of Myb to c-myc (Table $1)$. Moderate responses were seen in four lymphoid lines from $B$ and $T$ lineages (6- to 10 -fold). The strongest responses were elicited in two myelomonocytic cell lines (20to 30 -fold), suggesting that myelomonocytic cells are especially permissive for this activation pathway.

The best activation was seen in cell lines which express low endogenous levels of c-Myb, such as our WEHI-3 and EL4 lines. Background transcription due to endogenous Myb is not high enough to interfere with trans activation. $70 \mathrm{Z} / 3$ pre-B cells contain high endogenous levels of $c-m y b$ which may contribute to the poor trans activation at the standard 1:1 ratio of Myb to c-myc. Higher concentrations of c-Myb (at a 4:1 ratio) did result in sixfold trans activation. To exclude the possibility that the magnitude of activation varied with amount of $\mathrm{c}-\mathrm{Myb}$ produced from the expression vector, Myb proteins were immunoprecipitated from transfected cell lines. Transfected Myb protein was efficiently produced in even poorly responding cell lines such as 402AX (data not shown). We conclude that the cell type influences how well Myb activates c-myc.

Myb induces expression of P1- and P2-initiated c-myc transcripts. The above results represent the measurement of CAT protein which may reflect changes in both RNA and protein levels. Here, we determined whether Myb activation caused specific increases in the levels of accurately initiated c-myc mRNAs and, if so, whether these increases were preferential for P1- or P2-initiated transcripts and whether they varied with cell lineage. We have found that CAT messages are unstable; hence, we cloned the 1.7-kb c-myc promoter fragment into a $\beta$-globin test plasmid for the purpose of stabilizing mRNA accumulation (3). This test plasmid was transfected into ELA T cells or WEHI-3 myelomonocytic cells with full-length or frameshift mutant Myb expression vectors. The RNA was isolated, and S1 nuclease protection was used to detect levels of endogenous and plasmid-derived c-myc mRNAs. Plasmid-derived transcripts were distinguished from endogenous c-myc transcripts by an additional $118 \mathrm{bp}$ of $\beta$-globin sequence protected in the RNA-DNA probe hybrids. A map of pMyc-globin and resulting S1 hybrids is shown at the top of Fig. 1. Autoradiography from short (lanes 1 to 3 and 7 to 9 ) and long (lanes 4 to 6 and 10 to 12) exposures is shown to better reveal changes in P2 and P1 transcript levels, respectively, because the P2 signal is much stronger than the P1 signal (bottom of Fig. 1).

Myb effectively induced expression of c-myc mRNAs from the cotransfected pMyc-globin plasmid in EL4 cells (compare Myb-induced results in lanes 2 and 5 with uninduced results in lanes 1 and 4, respectively). Cells transfected with a promoterless pBS-globin test plasmid did not express Myc-globin transcripts, as expected (lanes 3 and 6). Both P1 and P2 transcripts were induced by Myb. While it is clear that both authentic transcripts are induced from the test plasmid, changes in the expression of endogenous c-myc gene were not detected, most likely because the transfected cells, and hence Myb-induced transcripts, represent a small fraction of the total cells. WEHI-3 cells were also studied since myelomonocytic cells are the preferred targets for Myb transformation in chickens $(25,31,48)$ and because c-myc was effectively activated by Myb in these cells (Table 1). Identical increases in P1 and P2 transcript levels were observed (Fig. 1, lanes 7 to 12).

Since the Myb-induced accumulation of c-myc mRNAs could be regulated at the level of RNA stability, we inhibited



FIG. 1. S1 nuclease protection assay of Myb-induced mRNAs in EL 4 and WEHI-3 cells. A map of the pMyc-globin reporter plasmid is shown at the top. $\mathrm{Bg}, B g l \mathrm{II}$; Sm, SmaI. The dotted arrow represents the labeled primer extension product used in hybridization to transiently expressed mRNAs. S1 nuclease digestion yields mRNA-probe hybrids of various lengths which are represented by lines and labeled on the autoradiograph. Lanes 1 to 6 are samples from EL- 4 cells, and lanes 7 to 12 are samples from WEHI-3 cells. pMyc-globin reporter was included in lanes $1,2,4,5,7,8,10$, and 11 , and control reporter pBS-globin was included in lanes 3,6, 9, and 12. The wild-type Myb expression vector, pRmb3SVneo, was included in lanes $2,3,5,6,8,9,11$, and 12 , and frameshift mutant vector pJTmyb-fs was included in lanes $1,4,7$, and 10 . The autoradiograph was exposed for 5 days in lanes 1 to 3 and 7 to 9 and 2 weeks in lanes 4 to 6 and 10 to 12 .

transcription with actinomycin D and compared the decay of Myb-stimulated and unstimulated transcripts. The Mybinduced transcripts from the test plasmid appeared to decay with the same half-life (approximately $2 \mathrm{~h}$ ) as noninduced transcripts, suggesting that Myb induces c-myc transcription (data not shown).

Deletion mapping of the murine c-myc promoter reveals proximal and distal Myb response regions (MRRs) in the lymphoid cell line ELA. Our analysis for potential MREs revealed 16 potential sites spread throughout the murine c-myc promoter which contain the critical AAC motif contained in all Myb-binding sites (7, 23, 37, 56, 60). Ten Myb-binding sites were located upstream of the P1 start site, and six were located downstream of the P2 start site (numbered 1 to 16 in Fig. 2). Sites 3, 9, and 10 are perfect matches to one of the three consensus sequences $(7,23,37)$. Most others have single base pair mismatches outside of the critical AAC binding core. Site 4 contains, in addition to AAC, an important GYCR motif recently defined by Howe and Watson (23). Sites 13, 14, and 15 have several mismatches to the consensus, although sites 14 and 15 are conserved with the human c-myc promoter and bind Myb protein. Retention of a pyrimidine immediately $5^{\prime}$ to the AAC binding core was not considered critical in our analysis because of recent data (60) showing that purines are func- 


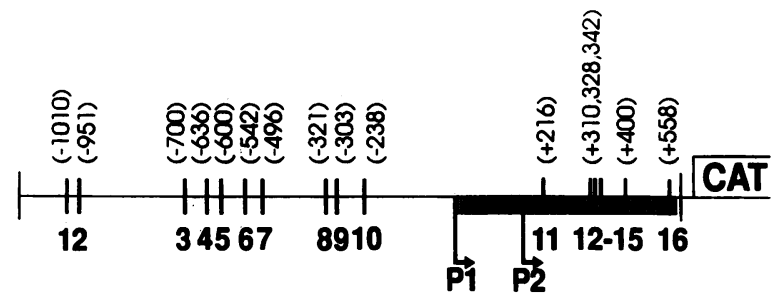

$$
\begin{aligned}
& \text { 1. } \overrightarrow{\text { GCAaacTGGCT }} \\
& \text { 2. } \overrightarrow{\text { TGGaacTGTGT }} \\
& \text { * 3. } \overrightarrow{\text { CATaactGTAC }} \\
& \text { 4. } \overleftarrow{\text { ATAaacAGCCA }} \\
& \text { 5. } \\
& \text { 6. } \overleftarrow{\text { ATCaacCCGCC }} \\
& \text { 7. GATaacTCATT } \\
& \text { 8. CTGaacTGTGT } \\
& \text { * 9. } \overrightarrow{\text { AACaacCGTAC }} \\
& \text { * 10. ATTaacTGCGC }
\end{aligned}
$$

FIG. 2. Myb-binding sites in the c-myc promoter. A map of the c-myc promoter fragment present in pMBgCAT is shown. Sixteen putative Myb-binding sites numbered from the $5^{\prime}$ end of the gene are listed. Their sequences are aligned according to the AAC consensus. Starred sequences are perfect matches to a consensus $(7,22,37)$. Left arrow, coding strand; right arrow, noncoding strand. See text for details.

tional in this context. Gel shift analyses with v-Myb protein produced by Escherichia coli confirmed that Myb bound to these putative binding sites (data not shown).

To define the relevant Myb-responsive target sequences, deletions of the 1.7-kb c-myc fragment in the pMBgCAT reporter plasmid were initially assayed for Myb responsiveness by 1:1 cotransfection with a c-Myb expression vector into EL4 cells (Fig. 3A). To control for differences in transfection efficiency, these and subsequent experiments were repeated multiple times with at least two separate DNA preparations. The c-Myb expression vector elicited a 10- to 15-fold-higher level of CAT activity from the pMBgCAT reporter than a frameshift mutant of the Myb expression vector or a promoterless reporter construct. Myb activation of the mutant reporter genes was denoted as percent trans activation relative to that of the wild-type pMBgCAT construct, which was assigned a value of $100 \%$. Removal of 716 bp of 5 '-flanking myc sequences in pSmBgCAT yielded only $27 \%$ of the activation with pMBgCAT, whereas a pMBgCAT(96) construct truncated down to bp -179 relative to P1 was only slightly less active than pSmBgCAT. These data suggest that an MRR(s) resides between bp -1140 and -424 . The effect of this region was consistently observed in EL4; however, the quantitative effect varied somewhat among experiments. Deletion of bp -868 and -424 in the $\operatorname{pMBgCAT}(\Delta \mathrm{Bx}-\mathrm{Sm})$ construct exhibited only $34 \%$ of the wild-type response. Another downstream deletion mutant, $\operatorname{pMBg}(\Delta \mathrm{Hd}-\mathrm{Xh})$, was also relatively nonresponsive to $\mathrm{Myb}$ induction (22\% of wild-type response). This plasmid deletes a region of the noncoding first exon between +148 and +515 which includes the P2 start site and most of the downstream sequence. Deletion of $\mathrm{P} 2$ in $\mathrm{pMBgCAT}(2-36)$ did not produce a decrease in CAT expression. This is in accord with a previous report (2) which showed that this same deletion increases the constitutive activity of the $\mathrm{P} 1$ promoter. It is likely that $\mathrm{P} 1$ compensates for the $\mathrm{P} 2$ deletion.

To further localize the response region within the first exon, either half of this +148 to +515 region was deleted. In this representative experiment (Fig. 3B), deletion of either half had no significant effect compared with deletion of both halves, which was only $33 \%$ as active as the wild type. These data suggest that either half can compensate for the other, as confirmed by later mutagenesis studies (see Tables 2 and 3). In Fig. 3B, deletion of the distal MRR between bp -1140 and -424 (pSmBgCAT plasmid) increased background transcription as it decreased Myb induction. This effect was consistent for three different DNA preparations and may reflect the deletion of a lymphoid-specific dehancer element previously mapped to this region (44). The dual use of a distal and a proximal response region was also observed in another T-cell line, BW5147 (Table 1). These data suggest that the Myb activation of c-myc in T-cell lines requires two MRRs: (i) a distal site upstream of the P1 promoter between bp -868 and -424 and (ii) a proximal site including first-exon sequences between bp +148 and +515 .

Deletion mapping in myelomonocytic WEHI-3 cells reveals exclusive utilization of the proximal response region. To determine whether the same MRRs were utilized in other responder cell types, deletions of the 1.7-kb c-myc fragment in the pMBgCAT reporter plasmid were assayed for Myb responsiveness. The myelomonocytic cell line WEHI-3 was again chosen as an interesting model. As shown in Fig. 4A, the wild-type pMBgCAT reporter plasmid was stimulated $>30$-fold by c-Myb. Unexpectedly, truncation of the distal bp -1140 to -424 region which defines a distal MRR in ELA cells had no effect on WEHI-3 cells. This observation was confirmed four times. The MRR in WEHI-3 cells could be mapped to the first noncoding exon, as shown by Myb's ability to activate the pMBmBgCAT plasmid, which contains the first exon, but not the exonless pMSmBmCAT plasmid (Fig. 4A).

To determine whether the MRR in the first exon mapped to the same proximal bp +148 to +515 site utilized in EL4 cells, the corresponding HindIII-XhoI segment was deleted and shown to cause a significant loss $(95 \%)$ of Myb responsiveness (Fig. 4B). Deletion of either half of this region produced little effect, similar to EL4 cells. The utilization of the -1140 to -424 distal MRR in EL4 and BW5147 cells but not WEHI-3 cells suggests that Myb activates through this distal site in a T-cell-specific manner. All other cell types examined require only the proximal response region of c-myc for c-Myb trans activation (Table 1).

The first exon of c-myc is sufficient to confer Myb responsiveness to a heterologous promoter in WEHI-3 cells but not ELA cells. Since the proximal site appeared to be an important MRR in all cell types, this region was separated from the rest of the c-myc promoter and tested for its ability to confer Myb responsiveness to an enhancerless test plasmid. The plasmid pSVM $(\mathrm{H})_{\mathrm{R}} \mathrm{CAT}$ contains the HindIII-to-BglII fragment of c-myc's first exon cloned in its natural orientation downstream of the SV40 promoter. Myb induction of the $\operatorname{pSVM}(\mathrm{H})_{\mathrm{R}} \mathrm{CAT}$ reporter plasmid was compared between EL4 and WEHI-3 cells (Fig. 5) by using a $1: 1$ ratio of expression vector to reporter plasmid. pSVM(H) $)_{R}$ CAT was effectively activated by c-Myb in WEHI-3 cells (18.4-fold) but weakly (3-fold) in EL4 cells. A control test plasmid which only contains the SV40 promoter was activated less than twofold in both cell types. In the same experiments in EL4 cells, Myb stimulated the full-length c-myc promoter test plasmid, pMBgCAT, which contains both MRRs. The 

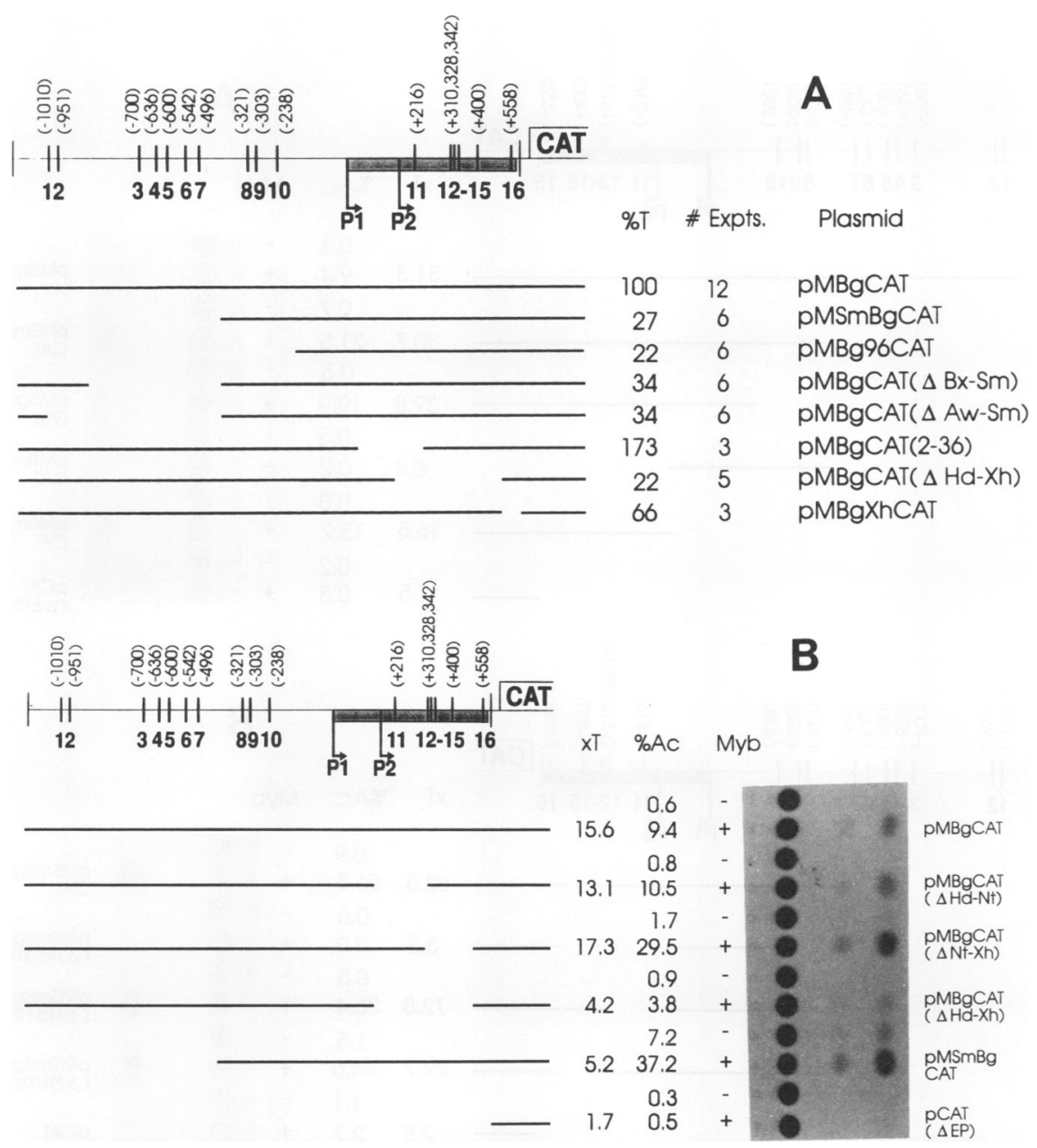

FIG. 3. Myb trans activation of mutated c-myc-CAT reporter genes in lymphoid EL4 cells. A map of the wild-type c-myc-CAT construct is shown at the top of each panel. The P1 and P2 transcription start sites are marked with bent arrows. The first noncoding exon is marked by a shaded box. The positions of 16 putative Myb-binding sites are shown. Mutant reporter genes are listed in the far right column. Lines to the left of each plasmid name represent the promoter sequences present in each construct. Wild-type (pMBgCAT) and mutant reporter genes were cotransfected with wild-type Myb expression vector $\mathrm{pRmb3SVneo}(+)$ or a frameshift mutant, $\mathrm{pJTmyb}$-fs $(-)$. Percent acetylation (\%Ac) of the ${ }^{14} \mathrm{C}$-chloramphenicol substrate was measured, and the Myb-specific trans activation $(\times \mathrm{T})$ was calculated as the ratio of \%Ac with pRMb3SVneo/\%Ac with pJTmyb-fs. Relative trans activation (\%T) was calculated from the Myb-specific trans activations for the mutant reporter relative to $100 \%$ for the wild-type pMBgCAT reporter. (A) A summary of multiple experiments in which \% T was normalized to the wild-type vector included in every experiment. The average \%Ac for pMBgCAT was $3.5 \%$ in the absence of Myb and $42 \%$ in the presence of Myb. (B) Results of a representative experiment with EL4 cells which maps two MRRs in EL4 cells. Maps are not drawn to scale. See text for details.

BglII-SmaI distal MRR did not confer Myb responsiveness to an enhancerless test plasmid in either cell line (data not shown). These data confirm that a HindIII-BglII fragment of the first exon is sufficient as a Myb-inducible element in WEHI-3 cells but not in EL4 cells.

Site-specific mutagenesis of potential Myb-binding sites. To finely map the MREs in the c-myc promoter, potential Myb-binding sites from Fig. 2 were selected and mutated. This endeavor has been fraught with difficulties because of the large number of potential c-Myb-binding sites in this promoter. Furthermore, mutation of single or even a few sites has little effect on c-Myb trans activation (see below). Most of the efforts have been devoted to the Myb target sites in the first exonic region because (i) this region is important in all cell types tested, (ii) the effect is consistently large and not variable between experiments, and (iii) fewer c-Myb targets are involved, making the mutagenesis scheme more feasible. Five different potential sites were identified (sites 11 to 15 in Fig. 2) in this region. In three different experiments with ELA cells, significant residual activity was observed when one to four of these sites were mutated, and mutation of all five sites was essential for the near obliteration of Myb trans-activating activity (Tables 2 and 3). This strongly suggests that many of these sites may be redundant and agrees with data shown earlier in Fig. 3B and 4B. Similar results were observed in WEHI-3 cells (data not shown). Site-specific mutations were also made in the upstream sites. Mutation of sites 3 through 6 created little change in c-Myb trans activation (data not shown). It is likely that all of the upstream sites have to be simultaneously mutated to produce an effect.

Deletion mutants of the c-Myb protein reveal functional domains for activation of $\mathrm{c}-m y c$ gene expression. The previous data suggest that the c-myc promoter contains two larger 


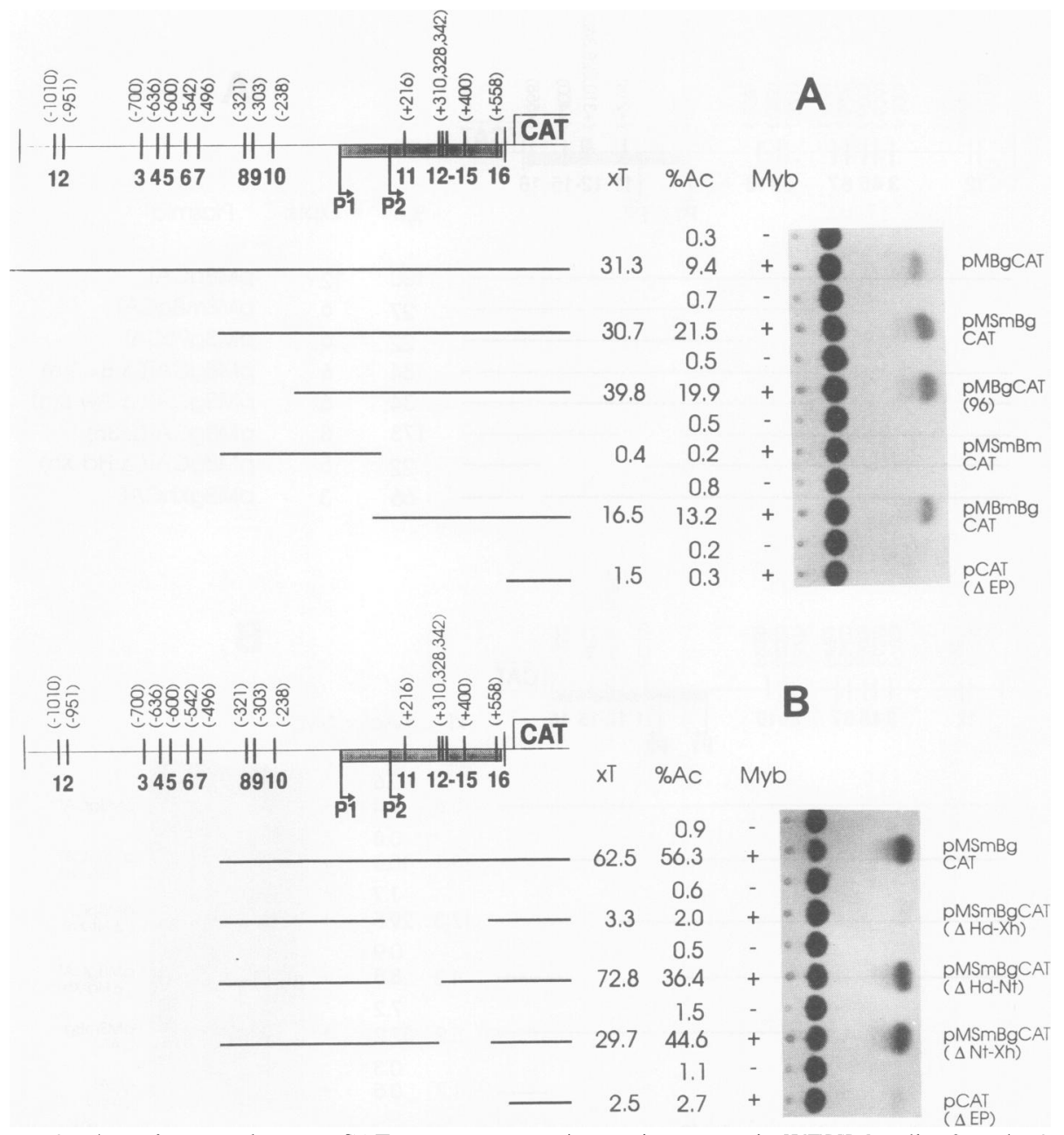

FIG. 4. Myb trans activation of mutated c-myc CAT reporter genes in myelomonocytic WEHI-3 cells. See the legend to Fig. 3 for an explanation of the map. Panels show results of representative experiments which map the Myb response to a proximal site in the c-myc first exon.

MRRs and that each MRR contains several potential Mybbinding sites. The loss of Myb responsiveness associated with mutagenesis of the first-exon MREs implicates DNA binding. Recombinant $\mathrm{V}-\mathrm{Myb}$ also binds to this region in a gel shift assay (data not shown). To further assess the DNA binding requirement, mutant $\mathrm{c}-\mathrm{Myb}$ proteins were assayed for their ability to trans activate the wild-type c-myc reporter gene. Figure 6A shows the c-Myb protein with the locations of its three regulatory domains: the DNA-binding domain, the trans-activator domain, and the negative regulatory domain. $\triangle T$ TA contains an internal deletion of the trans activator domain. $\triangle B A L I$ has a carboxyl-terminal truncation which removes the trans activator domain but retains the DNA-binding domain. $W \rightarrow G$ contains a point mutation which replaces the last tryptophan in the R3 domain (amino acid 185) with a glycine and affects the ability of this mutant protein to bind DNA (45).

EL4 cells were transfected with the wild-type or mutant Myb expression vectors and pMBgCAT, and the results of three experiments were averaged (Fig. 6B). The wild-type expression vector, pRmb3SVneo, elicited 23.4- and 51.5-fold activations at $1: 1$ and 2:1 ratios of $\mathrm{Myb}$ expression vector pMBgCAT, respectively. pMBgCAT was trans activated only twofold by the $W \rightarrow G$ mutant, suggesting that trans activation was dependent on DNA-binding function. $\triangle T A$ was approximately $15 \%$ as active as wild-type Myb expression vector. The significant eightfold activation at the $2: 1$ ratio suggests that other regions of the protein may have weak trans-activator function or that $\mathrm{Myb}$ function is coupled to other proteins with activator function in EL4 cells. The expression of all the mutant proteins was confirmed by immunoprecipitation analyses (data not shown). Parallel studies with WEHI-3 cells showed similar requirements for the DNA-binding and trans-activator domains with the following exception: $\triangle$ TA was not able to trans activate c-myc at all in WEHI-3 cells (data not shown).

To independently assess the necessity for DNA binding in c-myc activation, nonfunctional mutants $\triangle \mathrm{BALI}$ and $\mathrm{W} \rightarrow \mathrm{G}$ were cotransfected with pRmb3SVneo into EL4 and assessed for their ability to trans-dominantly repress activation by wild-type Myb protein (Fig. $6 \mathrm{C}$ ). The $\triangle \mathrm{BALI}$ mutant, which encodes the DNA-binding domain of c-Myb, would be expected to produce proteins which saturate DNA-binding sites in vivo and prevent binding by wild-type c-Myb protein. In two independent experiments, $\triangle \mathrm{BALI}$ repressed activation by wild-type c-Myb to 52 and $27 \%$ of control values; the average result of both experiments $(39 \%$ of wild-type) is shown. $W \rightarrow G$ had no effect in either experi- 


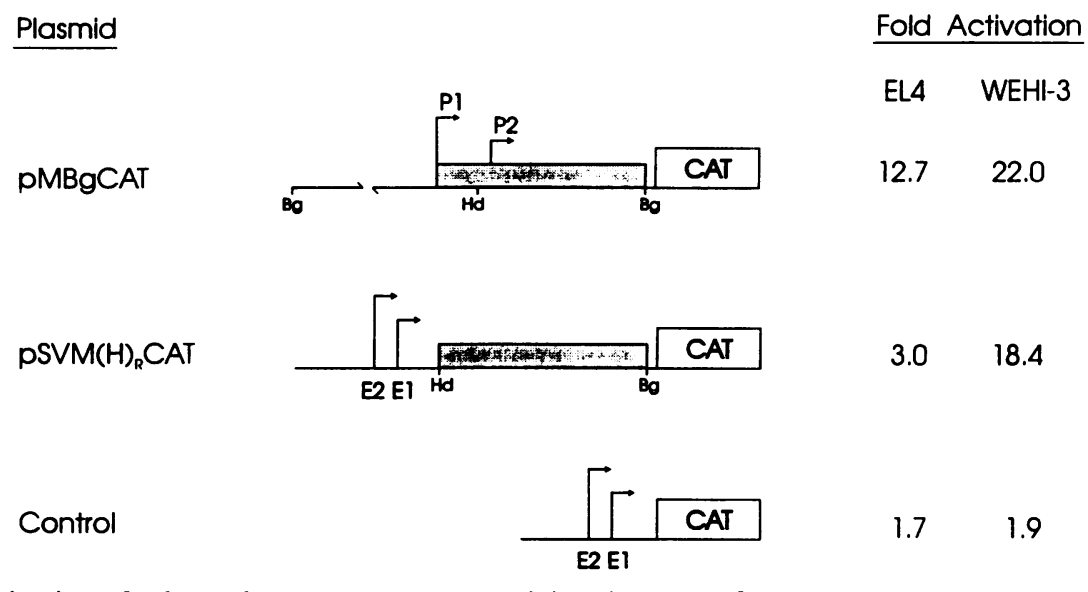

FIG. 5. Myb trans activation of a heterologous promoter containing the c-myc first exon sequence. Maps of the wild-type pMBgCAT reporter plasmid, heterologous promoter test plasmid pSVM $(\mathrm{H})_{\mathrm{R}} \mathrm{CAT}$, and control enhancerless SV40 promoter are shown. Bg, BglII; Hd, HindIII. These reporter genes were cotransfected at 1:1 ratios with wild-type or frameshift mutant Myb expression vectors. Myb-specific transactivations elicited in EL4 and WEHI-3 cells were calculated as described in the legend to Fig. 3 and are shown to the right. E1 and E2 are the transcription start sites for the SV40 promoter. The data are averaged from five experiments each with EL4 and WEHI-3.

ment. These data also suggest that DNA binding is necessary for the in vivo activation of c-myc gene expression.

Myb activation of c-myc gene expression does not require de novo protein synthesis in ELA and WEHI cells. Myb activation of at least one other gene appears to require protein synthesis (9). While Myb activation of c-myc is in part direct, we have not excluded a mechanism by which Myb induces another gene whose product is also necessary for Myb activation. To analyze the requirement for protein synthesis in Myb activation of $c-m y c$, a conditional system in which the hormone-binding domain of the estrogen receptor is fused near the carboxyl terminus of AMV v-Myb to produce a chimeric protein which is hormone responsive was used. In this construct the last 16 amino acids of the Myb protein are absent but the rest of the $v$-Myb coding region is intact. Previous work has shown that the hormone-binding domains of steroid receptors exhibit hormone-dependent inactivation functions and that their fusion to heterologous proteins makes these proteins hormone dependent $(9,41)$.

Estrogen-dependent activation of Myb-regulated genes had been studied only in stable transfectants (9); it was important to determine whether this system would work in a transient expression system. Likewise, the only available v-Myb-estrogen receptor test construct (constructed by U.E. in the laboratory of Joe Lipsick) contains an additional amino-terminal deletion as well as several mutations compared with c-Myb. We cotransfected a v-Myb-estrogen receptor expression vector along with the wild-type pMBgCAT reporter and allowed $24 \mathrm{~h}$ for the synthesis and accumulation of the fusion protein. The cells were treated

TABLE 2. Site-specific mutagenesis of Myb-binding sites

\begin{tabular}{ccc}
\hline Site $^{a}$ & Wild type & Mutant $^{b}$ \\
\hline 11 & TCCAACCGTCC & TCGCTAGCTCC \\
12 & CCCAACCCCTG & CCGTTGCCCTG \\
13 & CCCAACATCAG & CCGTTGATCAG \\
14 & CGCAACCCTCG & CGGCATGCTCG \\
15 & TGGAACTTACA & TGGAGGCCTCA \\
\hline
\end{tabular}

${ }^{a}$ Refer to Fig. 2.

${ }^{b}$ Underlinings represent mutated base pairs. with $1 \mu \mathrm{M} \beta$-estradiol, and CAT activity was measured after an additional $24 \mathrm{~h}$ (Fig. 7A). Prior to estrogen induction, a control expression vector encoding wild-type AMV v-Myb protein (pNEO-AMV) showed strong induction of the c-myc promoter while an empty expression vector (pNeo-MAVCLA) or the Myb-estrogen expression vector (pNEOMyb-E) elicited low CAT activities. Addition of estrogen strongly activated the chimeric protein's ability to activate c-myc, as shown by the 10 -fold increase in CAT activity. Estrogen addition had no effect on either control (the result of a CAT assay under conditions of nonlimiting substrate is shown in parentheses for pNEO-AMV). Thus, Myb activation of the c-myc promoter has been made estrogen dependent for $\mathrm{pNEO}-\mathrm{Myb}-\mathrm{E}$ through linkage of the ligand-binding domain of estrogen receptor to $\mathrm{v}$-Myb protein. The ability of $\mathrm{v}-\mathrm{Myb}$ itself to activate c-myc also suggests that a truncated and transforming Myb protein is still capable of activating c-myc gene expression.

To determine whether c-myc could be activated by c-Myb in the absence of de novo protein synthesis, we cotransfected pNEO-Myb-E with the pMyc-globin reporter and measured estrogen induction of c-myc mRNA in the presence and absence of cycloheximide. After $24 \mathrm{~h}$ to allow accumulation of the fusion protein, cycloheximide was added to test cultures $20 \mathrm{~min}$ prior to the addition of estrogen. After an additional 5 h, RNA was harvested and analyzed by $S 1$ protection analysis. A representative one of three experiments is shown in Fig. 7B.

TABLE 3. trans activation of mutant c-myc promoter by c-Myb

\begin{tabular}{|c|c|}
\hline Plasmid & $\begin{array}{l}\text { trans activation } \\
\text { (fold })^{a}\end{array}$ \\
\hline pMBgCAT & 18.7 \\
\hline pMSmBgCAT. & 11.8 \\
\hline $\operatorname{pMBg}(\Delta \mathrm{Hd}-\mathrm{Xh})$ & 5.1 \\
\hline 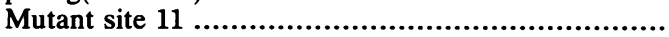 & 12.8 \\
\hline Mutant sites $11+12+13+14 \ldots$. & 12.4 \\
\hline 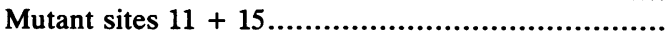 & 8.0 \\
\hline Mutant sites $11+12+13+14+15 \ldots \ldots \ldots \ldots \ldots \ldots . . .$. & 2.1 \\
\hline (a) & 1.9 \\
\hline
\end{tabular}

${ }^{a}$ Results are averages from three experiments. 


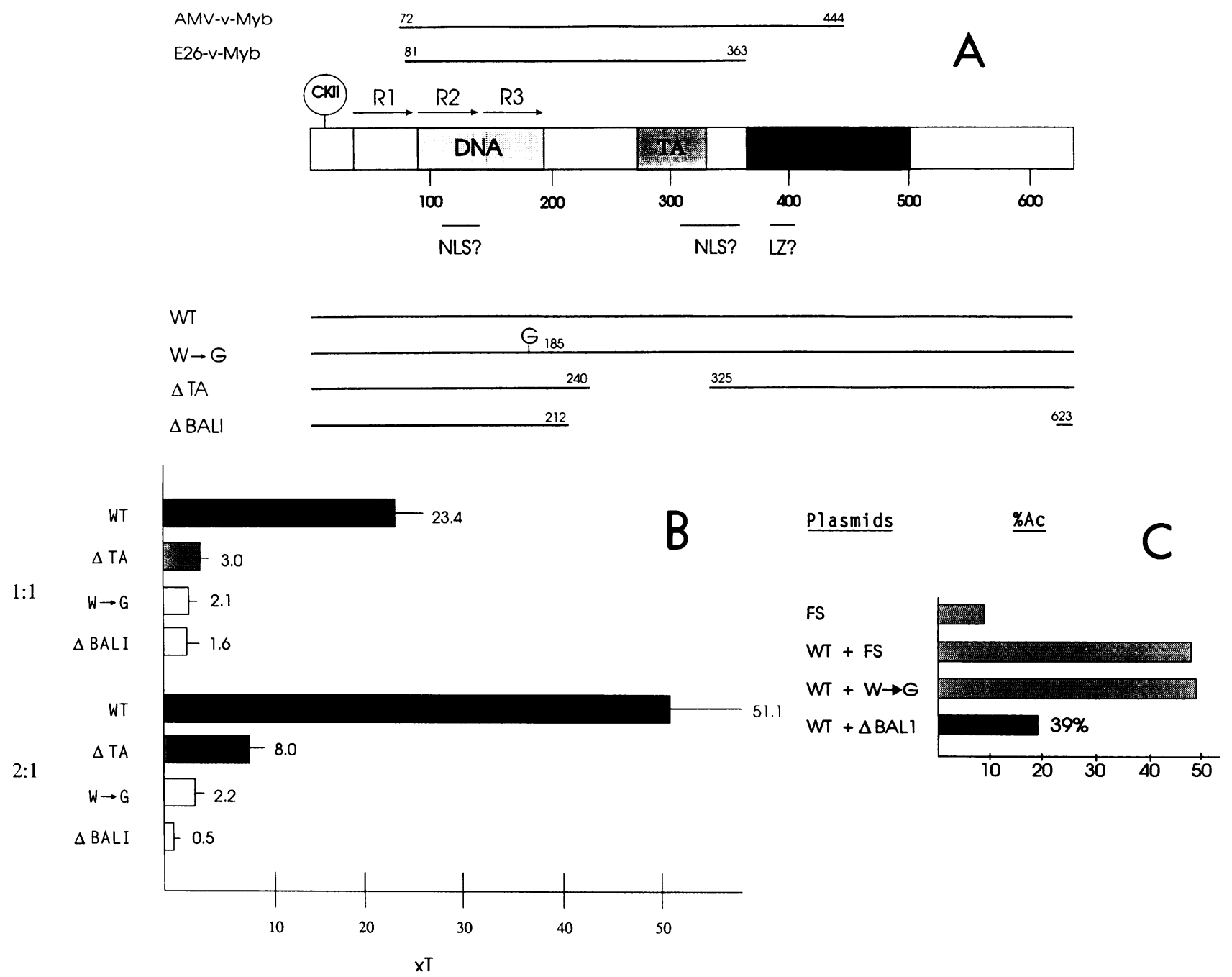

FIG. 6. Myb domains important for c-myc activation in EL4 cells. (A) A model of the c-Myb protein is shown. Regulatory domains are represented by name (DNA, DNA-binding domain; TA, trans-activator domain; NR, negative regulatory domain), and their locations are revealed as shaded boxes. Arrows marked R1, R2, and R3 show the location of the triple repeat structure. The circle labelled CKII shows the amino-terminal location of important CKII phosphorylation sites. Lines marked NLS and LZ show locations of putative nuclear localization and leucine zipper motifs. Mutant Myb proteins are represented by names to the left and by lines below the model. The deleted domains are represented by gaps in the lines. (B) A bar graph summary of three experiments with EL4 using these Myb mutants to trans activate expression from pMBgCAT is shown. The ratios of c-Myb expression vector to c-myc CAT reporter construct are on the left. Myb-specific trans activations $(\times T)$ are shown to the right of each bar. Lines through the center of each bar show standard errors. (C) Use of trans-dominant mutants to show that DNA binding is necessary for inducing c-myc gene expression. A bar graph summary of two experiments is shown. Nonfunctional c-Myb mutant expression vectors (i.e., W $\rightarrow$ G, $\triangle B A L I$, and frameshift mutant [FS]) were cotransfected 1:1 with wild-type (WT) Myb expression vectors into EL4 cells, and CAT activity (expressed as percent acetylation [\%Ac]) of the pMBgCAT reporter gene was measured. $\triangle$ BALI repressed activation by the WT Myb to $39 \%$ of control (WT + FS).

In EL4 cells, a 5-h estrogen induction induced approximate fourfold and twofold increases in P1- and P2-initiated c-myc transcripts, respectively, as determined by densitometric measurements (Fig. 7B, lane 1 versus lane 2). This degree of induction was lower than that observed in Fig. 1 because some Myb protein was made in the absence of estrogen induction, thus contributing to a high baseline. Nonetheless, treatment with cycloheximide did not significantly affect the level of c-myc (Fig. 7B, lane 3). Induction with estrogen in the presence of cycloheximide resulted in equivalent enhancement of mRNA levels to those of the samples treated with cycloheximide alone (lane 4). Again, the Myb protein appeared not to affect endogenous c-myc levels (lanes 1 to 4). These data indicated that Myb induction in EL4 cells does not require additional de novo protein synthesis. Similar studies were performed with WEHI-3 cells with similar results (data not shown).

\section{DISCUSSION}

Myb activation of c-myc gene expression involves a potentially important regulatory cascade in vivo between two proto-oncogene transcription factors. Myb and Myc each share a common function in that they control cell proliferation and differentiation $(13,31,32,48)$. Their linked expression is probably not related to coexpression, since c-Myb and c-Myc are not known to interact with each other. c-Myc heterodimerizes preferentially with Max, another member of 

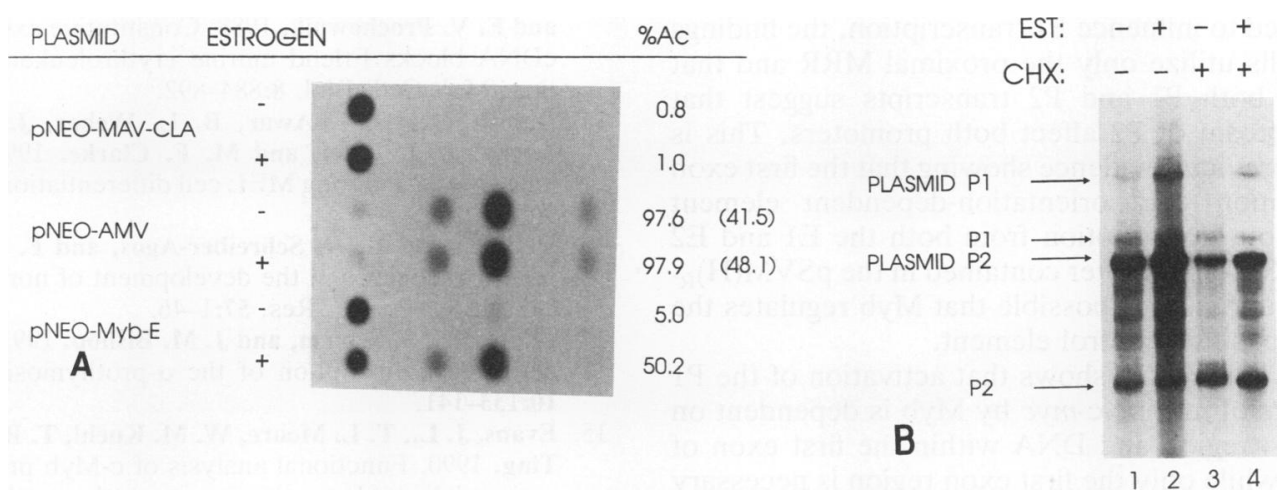

FIG. 7. Estrogen-dependent activation of c-myc-CAT expression by Myb-estrogen receptor fusion protein in EL4 cells. (A) The effect of estrogen addition $(+)$ or exclusion $(-)$ on the activation of pMBgCAT reporter plasmid by Myb-less control (pNEO-MAV-CLA), wild-type AMV (pNEO-AMV), and AMV-estrogen receptor (pNEO-Myb-E) expression vectors is assessed by CAT enzyme assay. A representative experiment with EL4 cells demonstrating estrogen-dependent activation of Myb-estrogen receptor activity is shown. Percent acetylations (\%Ac) are listed on the right. Numbers in parentheses are values obtained when samples were repeated under conditions of nonlimiting substrate. (B) S1 nuclease protection analysis. Cells cotransfected with pNEO-Myb-E and pMyc-globin were (lane 2 and 4) or were not (lanes 1 and 3) treated with estrogen. Lanes 3 and 4 were treated with cycloheximide; lanes 1 and 2 were not treated with the inhibitor. See the legend to Fig. 1 for an explanation of $\mathrm{S} 1$ nuclease protection analysis and size of RNA-probe hybrids.

the helix-loop-helix/leucine zipper class of transcription factors $(8,43)$, while Myb partners are not yet known. We hypothesize that c-Myb plays a central role in the control of hematopoietic cell proliferation and differentiation through its ability to regulate c-myc gene expression. An argument against this possibility is the finding that c-myc usually precedes c-myb expression. However, recent evidence in Drosophila cells shows that the functional effect of c-Myb is observed as late as the $G_{2}$ phase of the cell cycle (27a). An attractive possibility is that c-Myb from a previous cell cycle is up-regulating c-myc gene expression in the following cycle.

Those cell types which were most permissive (i.e., allowed the greatest response) are also those which express Myb in vivo or are transformed by Myb. For example, hematopoietic cells, especially immature cells, are the primary expressors of $\mathrm{c}-\mathrm{Myb}$ in vivo. Likewise, myelomonocytic and B-lymphoid cells are transformed by avian leukemia viruses or by retroviral insertion into the Myb locus (25, $27,42)$. The observation that some cell types are relatively nonresponsive despite our provision of a Myb expression vector (Table 1) suggests that mere expression of c-Myb is not sufficient to drive c-myc gene expression. Perhaps cellspecific factors modify Myb's function or restrict the c-myc promoter's ability to be activated. We suggest that these cell-specific factors facilitate Myb's ability to activate c-myc and ultimately control cell proliferation and differentiation or the process of Myb transformation.

Whether the cell type controls Myb activation by modifying Myb itself or facilitating c-myc's ability to be activated is unknown. Experiments presented here revealing a cell-typespecific use of MREs between $T$ cells and other cell types suggest the latter. Myb activation of c-myc in EL4 and BW5147 cells requires both proximal and distal response regions (Fig. 3 and Table 1). We additionally have seen that virtually all activation in WEHI-231 and WEHI-3 cells occurs through the proximal region (data summarized in Table 1). These data show that c-myc's first exon is an important MRR in all cell types but that the region upstream of the P1 start site promotes Myb activation in T cells. The observation that the HindIII-BglII first-exon fragment is sufficient to confer Myb responsiveness to a heterologous promoter in WEHI-3 but not EL4 cells (Fig. 5) supports this notion of response region preference. However, our demonstration that mutations in the proximal region binding sites block Myb trans activation suggests that the first exon is necessary but not sufficient for the Myb response in $\mathrm{T}$ cells.

Despite cell-specific influences, data presented here suggests that Myb's effect involves binding to Myb consensus elements in the c-myc first exon. Prior to this study, a direct link between the presence of Myb regulatory elements and trans activation by Myb has been established only for the mim-1 and human c-myb genes $(39,40)$. A necessity for DNA binding by Myb is shown here by demonstrations that the DNA-binding domain of the c-Myb protein is necessary for Myb function and that mutagenesis of putative Mybbinding sites within c-myc's first exon blocks trans activation. The DNA-binding domain of c-Myb was also shown to be necessary for activation of the human c-myc gene (36), but this is the first demonstration linking Myb activation to specific binding sites. Cofactor requirements are potentially indicated for the Hsp70 gene, in which Myb regulation occurs in the absence of DNA binding (28), and for the MD-1 gene, in which de novo protein synthesis is required for Myb regulation (9). For this reason we used a conditional system to test whether Myb could activate c-myc in the absence of de novo protein synthesis (Fig. 7). These data suggest that Myb can activate c-myc in the absence of de novo protein synthesis and that labile proteins which modulate basal c-myc transcription are not linked to the Myb activation pathway (38). These experiments do not rule out cofactors with long half-lives. We suggest that if these cofactors exist, they are cell specific and influence how Myb interfaces with c-myc. These factors may modify Myb itself by posttranslational modification or behave as coactivator proteins on the c-myc promoter.

Which c-myc transcripts are induced by Myb has not been reported previously. In this paper we show that c-Myb appears to show little promoter preference in activating c-myc transcription. Previous work suggests that the P1 and P2 promoters of $c-m y c$ are regulated independently $(2,58)$. Elements within the first 100 bp upstream of P1 affect P1 activity, while elements in the first exon sequence upstream of P2 affect P2 activity (2). While elements upstream of P1 
would be expected to influence $\mathrm{P} 1$ transcription, the findings that WEHI-3 cells utilize only the proximal MRR and that Myb stimulates both $\mathrm{P} 1$ and $\mathrm{P} 2$ transcripts suggest that elements downstream of $\mathbf{P} 2$ affect both promoters. This is consistent with previous evidence showing that the first exon contains a position- and orientation-dependent element which can promote transcription from both the E1 and E2 start sites of the SV40 promoter contained in the $\operatorname{pSVM}(\mathrm{H})_{\mathrm{R}^{-}}$ CAT test plasmid (58). It is possible that Myb regulates the function of this positive control element.

In conclusion, this report shows that activation of the P1 and $\mathrm{P} 2$ promoters of murine c-myc by Myb is dependent on a distal upstream region and DNA within the first exon of c-myc in T cells while only the first exon region is necessary in other cells. Both of these regions contain functional Myb-binding sites. Myb's activity in this system is mediated by two domains, the DNA-binding and trans-activator domains. In addition to Myb, other labile proteins do not play a role in this process. These studies have elucidated many features of the trans activation of c-myc by Myb which serves as a model for the function of Myb in biologically important systems.

\section{ACKNOWLEDGMENTS}

Special thanks are given to Mary Davis for heroic secretarial assistance, Albert Baldwin and Steven Hunt for reviewing the manuscript, and Joe Lipsick for providing v-Myb-expressing $E$. coli and $\mathrm{v}$-Myb-estrogen receptor fusion vector.

This work was supported by NIH grants RO1-CA48185 and AI29564, a Jefferson Pilot Award, and an American Cancer Society Faculty Award to J.P.-Y.T.; NCI grant CA36246 to K.B.M.; and grant 2663 from the Council for Tobacco Research to T.B. J.P.C. is a Special Fellow of the Leukemia Society of America. U.E. was supported by ROI-CA43592 awarded to J. Lipsick.

\section{REFERENCES}

1. Anfossi, G., A. M. Gewirtz, and B. Calabretta. 1989. An oligomer complementary to c-myb-encoded mRNA inhibits proliferation of human myeloid leukemia cell lines. Proc. Natl. Acad. Sci. USA 86:3379-3383.

2. Asselin, C., A. Nepveu, and K. B. Marcu. 1989. Molecular requirements for transcriptional initiation of the murine c-myc gene. Oncogene 4:549-558.

3. Aviv, H., V. Valloch, R. Bastos, and S. Levy. 1976. Biosynthesis and stability of globin mRNA in cultured erythroleukemia friend cells. Cell 8:495-503.

4. Bender, T. P., and W. M. Kuehl. 1986. Murine myb protooncogene mRNA: cDNA sequence and evidence for $5^{\prime}$ heterogeneity. Proc. Natl. Acad. Sci. USA 83:3204-3208.

5. Bender, T. P., and W. M. Kuehl. 1987. Differential expression of the c-myb proto-oncogene marks the pre-B/B cell junction in murine B lymphoid tumors. J. Immunol. 139:3822-3827.

6. Berk, A. J., and P. A. Sharp. 1977. Sizing and mapping of early adenovirus mRNAs by gel electrophoresis of S1 endonuclease digested hybrids. Cell 12:721-732.

7. Biedenkapp, H., U. Borgemeyer, A. E. Sippel, and K.-H. Klempnauer. 1988. Viral myb oncogene encodes a sequence-specific DNA-binding activity. Nature (London) 335:835-837.

8. Blackwood, E. M., and R. N. Eisenman. 1991. Max: a helix-loophelix zipper protein that forms a sequence-specific DNA-binding complex with Myc. Science 251:1211-1217.

9. Burk, O., and K.-H. Klempnauer. 1991. Estrogen-dependent alterations in differentiation state of myeloid cells caused by a v-Myb/estrogen receptor fusion protein. EMBO J. 10:37133719.

10. Chirgwin, J. M., A. E. Przybyla, R. J. MacDonald, and W. J. Rutter. 1979. Isolation of biologically active ribonucleic acid from sources enriched in ribonuclease. Biochemistry 18:5294 5299.

11. Clarke, M. F., J. F. Kukowska-Latallo, E. Westin, M. Smith, and E. V. Prochownik. 1988. Constitutive expression of a c-myb cDNA blocks Friend murine erythroleukemia cell differentiation. Mol. Cell. Biol. 8:884-892.

12. Danish, R., O. El-Awar, B. L. Weber, J. Langmore, L. A. Turka, J. J. Ryan, and M. F. Clarke. 1992. Myb effects on kinetic events during MEL cell differentiation. Oncogene 7:901907.

13. DePinho, R. A., N. Schreiber-Agos, and F. W. Alt. 1991. myc family oncogenes in the development of normal and neoplastic cells. Adv. Cancer Res. 57:1-46.

14. Eilers, M., S. Schirm, and J. M. Bishop. 1991. The Myc protein activates transcription of the $\alpha$-prothymosin gene. EMBO J. 10:133-141.

15. Evans, J. L., T. L. Moore, W. M. Kuehl, T. Bender, and J. P.-Y. Ting. 1990. Functional analysis of c-Myb protein in T-lymphocytic cell lines shows that it trans-activates the c-myc promoter. Mol. Cell. Biol. 10:5747-5752.

16. Furukawa, Y., H. Piwnica-Worms, T. J. Ernst, Y. Kanakura, and J. D. Griffin. 1990. $c d c 2$ gene expression at G1 to S transition in human T lymphocytes. Science 250:805-808.

17. Garcia, A., K. LaMontagne, D. Reavis, U. Stober-Grasser, and J. S. Lipsick. 1991. Determinants of sequence-specific DNAbinding by $\mathrm{p} 48^{\mathrm{v}-\mathrm{myb}}$. Oncogene 6:265-273.

18. Gewirtz, A. M., G. Anfossi, D. Venturelli, S. Valpreda, R. Sims, and B. Calabretta. 1989. $G_{1} / S$ transition in normal human T-lymphocytes requires the nuclear protein encoded by c-myb. Science 245:180-183.

19. Gewirtz, A. M., and B. Calabretta. 1988. A c-myb antisense oligodeoxynucleotide inhibits normal hematopoiesis in vitro. Science 242:1303-1306.

20. Grasser, F. A., T. Graf, and J. S. Lipsick. 1991. Protein truncation is required for the activation of the c-myb protooncogene. Mol. Cell. Biol. 11:3987-3996.

21. Holt, J. T., R. L. Redner, and A. W. Nienhuis. 1988. An oligomer complementary to c-myc mRNA inhibits proliferation of HL-60 promyelocytic cells and induces differentiation. Mol. Cell. Biol. 8:963-973.

22. Howe, K. M., C. F. L. Reakes, and R. J. Watson. 1990. Characterization of the sequence-specific interaction of mouse c-myb protein with DNA. EMBO J. 9:161-168.

23. Howe, K. M., and R. J. Watson. 1991. Nucleotide preferences in sequence-specific recognition of DNA by c-myb protein. Nucleic Acids Res. 19:3913-3919.

24. Hu, Y., R. G. Ramsay, C. Kanei-Ishii, and T. J. Gonda. 1991. Transformation by carboxy-deleted Myb reflects increased transactivating capacity and disruption of a negative regulatory domain. Oncogene 6:1549-1553.

25. Ibanez, C. E., and J. S. Lipsick. 1988. Structural and functional domains of the $m y b$ oncogene: requirements for nuclear transport, myeloid transformation, and colony formation. J. Virol. 62:1981-1988.

26. Kanei-Ishii, C., E. M. MacMillan, T. Nomura, A. Sarai, R. G. Ramsay, S. Aimoto, S. Ishii, and T. J. Gonda. 1992. Transactivation and transformation by Myb are negatively regulated by a leucine-zipper structure. Proc. Natl. Acad. Sci. USA 89:30883092.

27. Kanter, M. R., R. E. Smith, and W. S. Hayward. 1988. Rapid induction of B-cell lymphomas: insertional activation of c-myb by avian leukosis virus. J. Virol. 62:1423-1432.

27a.Kapzen, E., and J. M. Bishop. Submitted for publication.

28. Klempnauer, K.-H., H. Arnold, and H. Biedenkapp. 1989. Activation of transcription by $\mathrm{v}-m y b$ : evidence for two different mechanisms. Genes Dev. 3:1582-1589.

29. Krainer, A. R., T. Maniatis, B. Ruskin, and M. R. Green. 1984 Normal and mutant human B-globin pre-mRNAs are faithfully and efficiently spliced in vitro. Cell 36:993-1005.

30. Luscher, B., and E. Christenson, D. W. Litchfield, E. G. Krebs, and R. N. Eisenman. 1990. Myb DNA binding inhibited by phosphorylation at a site deleted during oncogene activation. Science 344:517-521.

31. Luscher, B., and R. N. Eisenman. 1990. New light on Myc and Myb. Part II. Myb. Genes Dev. 4:2235-2241.

32. Marcu, K. B., S. A. Bossone, and A. J. Patel. 1992. Myc function 
and regulation. Annu. Rev. Biochem. 61:809-860.

33. McClinton, D., J. Stafiord, L. Brents, T. P. Bender, and W. M. Kuehl. 1990. Differentiation of mouse erythroleukemia cells is blocked by late up-regulation of a c-myb transgene. Mol. Cell. Biol. 10:705-710.

34. McMahon, J., K. M. Howe, and R. J. Watson. 1988. The induction of Friend erythroleukemia differentiation is markedly affected by expression of a transfected c-myb cDNA. Oncogene 3:717-720.

35. Mucenski, M. L., K. McLain, A. B. Kier, S. H. Swerdlow, C. M. Schreiner, T. A. Miller, D. W. Pietryga, W. J. Scott, Jr., and S. S. Potter. 1991. A functional c-myb gene is required for normal murine fetal hepatic hematopoiesis. Cell 65:677-689.

36. Nakagoshi, H., C. Kanei-Ishii, T. Sawazaki, G. Mizuguchi, and S. Ishii. 1992. Transcriptional activation of the c-myc gene by the c-myb and B-myb gene products. Oncogene 7:1233-1240.

37. Nakagoshi, H., T. Nagase, C. Kanei-Ishii, Y. Ueno, and S. Ishii. 1990 . Binding of the $c-m y b$ proto-oncogene product to the simian virus 40 enhancer stimulates transcription. J. Biol. Chem. 265:3479-3483.

38. Nepveu, A., and K. B. Marcu. 1986. Intragenic pausing and anti-sense transcription within the murine c-myc locus. EMBO J. 5:2859-2865.

39. Ness, S. A., A. Marknell, and T. Graf. 1989. The v-myb oncogene product binds to and activates the promyelocytespecific mim-1 gene. Cell 59:1115-1125.

40. Nicolaides, N. C., R. Gualdi, C. Casadevall, L. Manzella, and B. Calabretta. 1991. Positive autoregulation of c-myb expression via Myb binding sites in the 5' flanking region of the human c-myb gene. Mol. Cell. Biol. 11:6166-6176.

41. Picard, D., S. J. Salser, and K. R. Yamamoto. 1988. A movable and regulable inactivation function within the steroid binding domain of the glucocorticoid receptor. Cell 54:1073-1080.

42. Pizer, E., and E. H. Humphries. 1989. RAV-1 insertional mutagenesis: disruption of the c-myb locus and development of avian B-cell lymphomas. J. Virol. 63:1630-1640.

43. Prendergast, G. C., D. Lawe, and E. B. Ziff. 1991. Association of myn, the murine homolog of max, with c-myc stimulates methylation-sensitive DNA binding and ras cotransformation. Cell 65:395-407.

44. Remmers, E. F., J.-Q. Yang, and K. B. Marcu. 1986. A negative control element located upstream of the murine c-myc gene. EMBO J. 5:899-904.

45. Saikumar, P., R. Murali, and E. P. Reddy. 1990. Role of tryptophan repeats and flanking amino acids in Myb-DNA interactions. Proc. Natl. Acad. Sci. USA 87:8452-8456.

46. Sakura, H., C. Kanei-Ishii, T. Nagase, H. Nakagoshi, T. J. Gonda, and S. Ishii. 1989. Delineation of three functional domains of the transcriptional activator encoded by the c-myb protooncogene. Proc. Natl. Acad. Sci. USA 86:5758-5762.
47. Selvakumaran, M., D. A. Liebermann, and B. Hoffman-Liebermann. 1992. Deregulated c-myb disrupts interleukin-6- or leukemia inhibitory factor-induced myeloid differentiation prior to c-myc: role in leukemogenesis. Mol. Cell. Biol. 12:2493-2500.

48. Shen-Ong, G. L. C. 1990. The Myb oncogene. Biochim. Biophys. Acta 1032:39-52.

49. Shen-Ong, G. L. C., K. Holmes, and H. C. Morse III. 1987. Phorbol ester-induced growth arrest of murine myelomonocytic leukemia cells with virus-disrupted Myb locus is not accompanied by decreased Myb and Myc expression. Proc. Natl. Acad. Sci. USA 84:199-203.

50. Sherman, P. A., P. V. Basta, T. L. Moore, A. M. Brown, and J. P.-Y. Ting. 1989. Class II box consensus sequences in the HLA-DR $\alpha$ gene: transcriptional function and interaction with nuclear proteins. Mol. Cell. Biol. 9:50-56.

51. Siu, G., A. L. Wurster, J. S. Lipsick, and S. M. Hedrick. 1992. Expression of the CD4 gene requires a Myb transcription factor. Mol. Cell. Biol. 12:1592-1604.

52. Thompson, C. B., P. B. Challoner, P. E. Neiman, and $M$. Groudine. 1986. Expression of the c-myb proto-oncogene during cellular proliferation. Nature (London) 319:374-380.

53. Todokoro, K., R. J. Watson, H. Higo, H. Amanuma, S. Kuramochi, H. Yanigisawa, and Y. Ikawa. 1988. Down-regulation of c-myb gene expression is a prerequisite for erythropoietininduced erythroid differentiation. Proc. Natl. Acad. Sci. USA 85:8900-8904.

54. Travali, S., K. Reiss, A. Ferber, S. Petralia, W. E. Mercer, B. Calabretta, and R. Baserga. 1991. Constitutively expressed c-myb abrogates the requirement for insulinlike growth factor 1 in 3T3 fibroblasts. Mol. Cell. Biol. 11:731-736.

55. Westin, E. H., R. C. Gallo, S. K. Arya, A. Eva, L. M. Souza, M. A. Baluda, S. A. Aaronson, and F. Wong-Staal. 1982. Differential expression of the $a m v$ gene in human hematopoietic cells. Proc. Natl. Acad. Sci. USA 79:2194-2198.

56. Weston, K. 1992. Extension of the DNA binding consensus of chicken c-Myb and v-Myb proteins. Nucleic Acids Res. 20: 3093-3049.

57. Weston, K., and J. M. Bishop. 1989. Transcriptional activation by the v-myb oncogene and its cellular progenitor, c-myb. Cell 58:85-93.

58. Yang, J.-Q., E. F. Remmers, and K. B. Marcu. 1986. The first exon of the c-myc proto-oncogene contains a positive control element. EMBO J. 5:3553-3562.

59. Yokoyama, K., and F. Imamoto. 1987. Transcriptional control of the endogenous $M Y C$ protooncogene by antisense RNA. Proc. Natl. Acad. Sci. USA 84:7363-7367.

60. Zobel, A., F. Kalkbrenner, S. Guehmann, M. Nawrath, G. Vordbrueggen, and K. Moelling. 1991. Interaction of the v- and c-Myb proteins with regulatory sequences of the human c-myc gene. Oncogene 6:1397-1407. 